\title{
The Interval-Valued Intuitionistic Fuzzy MULTIMOORA Method for Group Decision Making in Engineering
}

\author{
Edmundas Kazimieras Zavadskas, ${ }^{1}$ Jurgita Antucheviciene, ${ }^{1}$ \\ Seyed Hossein Razavi Hajiagha, ${ }^{2}$ and Shide Sadat Hashemi ${ }^{3}$ \\ ${ }^{1}$ Department of Construction Technology and Management, Vilnius Gediminas Technical University, Sauletekio Alejja 11, \\ LT-10223 Vilnius, Lithuania \\ ${ }^{2}$ Department of Management, Khatam Institute of Higher Education, No. 30, Hakim A'zam Alley, Mollasadra Street, \\ North Shiraz Avenue, Tehran 19941633356, Iran \\ ${ }^{3}$ Department of Management, Islamic Azad University, Kashan Branch, Kashan 8715998151, Iran
}

Correspondence should be addressed to Jurgita Antucheviciene; jurgita.antucheviciene@vgtu.lt

Received 12 March 2015; Revised 8 May 2015; Accepted 11 May 2015

Academic Editor: David Bigaud

Copyright ( 2015 Edmundas Kazimieras Zavadskas et al. This is an open access article distributed under the Creative Commons Attribution License, which permits unrestricted use, distribution, and reproduction in any medium, provided the original work is properly cited.

\begin{abstract}
Multiple criteria decision making methods have received different extensions under the uncertain environment in recent years. The aim of the current research is to extend the application of the MULTIMOORA method (Multiobjective Optimization by Ratio Analysis plus Full Multiplicative Form) for group decision making in the uncertain environment. Taking into account the advantages of IVIFS (interval-valued intuitionistic fuzzy sets) in handling the problem of uncertainty, the development of the interval-valued intuitionistic fuzzy MULTIMOORA (IVIF-MULTIMOORA) method for group decision making is considered in the paper. Two numerical examples of real-world civil engineering problems are presented, and ranking of the alternatives based on the suggested method is described. The results are then compared to the rankings yielded by some other methods of decision making with IVIF information. The comparison has shown the conformity of the proposed IVIF-MULTIMOORA method with other approaches. The proposed algorithm is favorable because of the abilities of IVIFS to be used for imagination of uncertainty and the MULTIMOORA method to consider three different viewpoints in analyzing engineering decision alternatives.
\end{abstract}

\section{Introduction}

Multicriteria decision making (MCDM) is a growing field of operations research both from theoretical and implementation perspectives. The importance of MCDM can be drawn from Zeleny [1]: "it has become more and more difficult to see the world around us in a uni-dimensional way and to use only a single criterion when judging what we see. We always compare, rank, and order the objects of our choice with respect to multiple criteria of choice." The MCDM field is further divided into two classes, including multiobjective decision making (MODM) and multiattribute decision making (MADM). These classes are, respectively, associated with planning and selection classification of Simon
[2] for decision making problems. The main topic of this paper covers MADM

A MADM problem can be formally characterized as the task to evaluate, compare, and rank a set of finite alternatives, options, or choices with regard to a set of finite attributes. According to $\mathrm{Yu}$ [3], a MADM problem is composed of the set of substitutive alternatives (1), the set of evaluation criteria (2), the outcome (or decision) matrix with regard to the alternatives scored based on the evaluation criteria (3), and the preference structure of decision making about the criterion significances or weights (4). The information about the third and fourth parts of a decision making problem is determined exactly. However, a decision maker always deals with approximate or partial information [4]. Therefore, 
exactness is an unrealistic assumption. Different frameworks have been proposed to handle uncertainty in practice. Liu and Lin [5] classified these frameworks into probability and statistics (1) and grey system theory and fuzzy set theory (2). Fuzzy set theory introduced by Zadeh [6] is widely applied to decision making problems. In other words, the fuzzy set theory is a generalization of ordinal sets, where a membership degree is assigned to each element of a set. Each type of uncertainty has its own characteristics and is appropriate for special cases. While probability is concerned with the occurrence of well-defined events, fuzzy sets deal with gradual concepts and describe their boundaries [7]. In fact, the fuzzy set theory is appropriate for recognition-based uncertainty that is common in decision making.

Determining a single membership degree is a difficult task for decision makers and, therefore, Grattan-Guinness [8] believes that presentation of a linguistic expression in the form of a fuzzy set is not sufficient. In 1986, Atanassov [9] introduced the notion of intuitionistic fuzzy sets (IFSs) as an extension of ordinal fuzzy sets. In addition to a membership degree of each element, IFS assigns a degree of nonmembership to each element. Later, Atanassov and Gargov [10] extended the interval-valued intuitionistic fuzzy sets (IVIFSs), where membership and nonmembership degrees are stated as closed intervals.

When it became obvious that the type 1 fuzzy sets were not always sufficient for MADM under uncertain environment, type 2 fuzzy sets, involving interval-valued as well as intuitionistic fuzzy sets, were proposed. As a result, the MULTIMOORA method was updated by using generalized interval-valued trapezoidal fuzzy numbers [11] or intuitionistic fuzzy numbers [12]. The method has been successfully applied to making economic, technological, or management decisions. The applications of various approaches in 20062013, including crisp and extended methods, were summarized by T. Baležentis and A. Baležentis [13]. The most recent applications cover the extended versions of the method, in particular, the fuzzy MULTIMOORA $[14,15]$ or MULTIMOORA based on the interval 2-tuple linguistic variables [16]. Also, Li [17] extended MULTIMOORA with hesitant fuzzy numbers, where membership degree of elements is defined over a set of different values.

The current research aims to extend the MULTIMOORA method, using the interval-valued intuitionistic fuzzy sets. Taking into account the advantages of IVIFS, the intervalvalued intuitionistic fuzzy MULTIMOORA (IVIF-MULTIMOORA) method for group decision making is presented in the paper. For this reason, three parts of MULTIMOORA were extended under IVIF information and the appropriate algorithm was proposed.

The paper is organized as follows. In Section 2, the literature review is presented and then the crisp version of MULTIMOORA is briefly overviewed in Section 3. Section 4 includes a brief description of the interval-valued intuitionistic fuzzy sets. The proposed IVIF-MULTIMOORA algorithm is presented in Section 5. The solution of two numerical examples of civil engineering problems is given in Section 6, while the results obtained are compared with the data yielded by some other methods of IVIF decision making. Finally, the discussion and the conclusions are presented in Sections 7 and 8.

\section{Literature Review}

Taking into account the flexibility and general character of IVIFS, researchers developed decision making methods under the IVIFS environment. Some researchers developed the well-known MADM methods in the IVIF form. Some authors [18-20] proposed different frameworks of TOPSIS method under the IVIF environment. Li [21, 22] developed some mathematical programming-based method to solve the MADM problems with both ratings of the alternatives on attributes and weights of attributes expressed with the help of IVIFS. Park et al. [23] presented an IVIF version of the VIKOR method. Li [24] proposed a closeness coefficient based on the nonlinear programming method for solving IVIF MADM problems. Chen et al. [25] solved the MADM problems based on the interval-valued intuitionistic fuzzy weighted average operator and newly defined fuzzy ranking method for intuitionistic fuzzy values. Yu et al. [26] introduced some IVIF aggregation operators and applied them to solving various decision making problems. Zhang and $\mathrm{Yu}$ [27] presented an optimization model to determine the attribute weights in an IVIF decision making problem and, then, used these weights in an extended TOPSIS to rank the alternatives. Ye [28] introduced a cosine similarity measure and a weighted cosine similarity measure to MADM problems. Meng et al. [29] also proposed two new aggregation operators, that is, the arithmetical interval-valued intuitionistic fuzzy generalized $\lambda$-Shapley Choquet operator and the geometric interval-valued intuitionistic fuzzy generalized $\lambda$ Shapley Choquet operator, and investigated their application to solving MADM problems. Meng et al. [30] used Shapley function in extending a generalized IVIF hybrid Shapley averaging operator and proposed its application to solving MADM problems. Razavi Hajiagha et al. [31] developed Complex Proportional Assessment (COPRAS) method with IVIF data. Chai et al. [32] proposed a rule-based decision model when decision information in a group decision making problem is provided as IVIF values. Wan and Dong [33] defined the possibility degree of comparison between two IVIF numbers and introduced two ordered averaging operators based on the Karnik-Mendel algorithm to solve MADM problems with IVIF information. Chen [34] developed a method based on the traditional linear assignment method for solving decision making problems in the IVIF context. $\mathrm{Xu}$ and Shen [35] presented the IVIF outranking choice method to solve MADM problems, while Zavadskas et al. [36] extended the IVIF weighted aggregated sum product assessment (WASPAS) method. Geetha et al. [37] proposed a new ranking method of IVIF numbers and extended its application in decision making problems. Zhang et al. [38] proposed a new definition of IVIF entropy an entropybased MADM method. Later, Wei, and Zhang [39] proposed applying an entropy measure for IFSs and IVIFSs to assess the experts' weights for multicriteria fuzzy group decision making. Tong and $\mathrm{Yu}$ [40] introduced a novel approach for 
ranking the alternatives based on the IVIF cross entropy and TOPSIS in the IVIF environment. Wu and Chiclana $[41,42]$ introduced a risk attitudinal ranking method for IVIF numbers and applied this ranking method in a MADM problem. They imposed a risk attitude parameter over IVIF numbers ordinal score and accuracy functions [43] and used this method for solving MADM problems.

As mentioned before the current paper has focused on the extension of the MULTIMOORA (Multiobjective Optimization by Ratio Analysis plus Full Multiplicative Form) method. This method belongs to the group of complete aggregation methods, based on the reference point technique. The crisp MOORA method (Multiobjective Optimization by Ratio Analysis) was presented by Brauers and Zavadskas in 2006 [44]. This method was further supplemented by the full multiplicative form. The MULTIMOORA was suggested by Brauers and Zavadskas in 2010 [45]. The method is based on the theory of dominance [46] and enables us to summarize MOORA, consisting of the ratio system and the reference point approaches, as well as the full multiplicative form. The robustness of the method has been proved [47] and it has been successfully applied to evaluate decisions by using a single approach or its combinations with other MADM methods, such as TOPSIS [48] and WASPAS [49, 50].

Several developments of MULTIMOORA for the uncertain environment have been presented. The fuzzy MULTIMOORA was suggested by Brauers et al. [52]. To overcome some drawbacks of the fuzzy set theory, the twotuple linguistic representation method for computing with words can be applied [53]. Accordingly, the considered method has been extended for group decision making based on two tuples (MULTIMOORA-2T-G) $[54,55]$. The fuzzy MULTIMOORA, based on triangular fuzzy numbers and designed for group decision making (MULTIMOORA-FG), was introduced $[56,57]$. As a further modification of the method, MOORA with grey numbers was developed $[58,59]$.

\section{MULTIMOORA}

The method summarizes three approaches, that is, MOORA, consisting of the ratio system and the reference point, and the full multiplicative form.

Regardless of the approach used, initial decision criteria are transformed by applying vector normalization:

$$
\bar{x}_{i j}=\frac{x_{i j}}{\sqrt{\sum_{i=1}^{m} x_{i j}^{2}}},
$$

where $x_{i j}$ is the initial criterion value, that is, the response of the alternative $i$ to objective $j ; i=1,2, \ldots, m$; $m$ is the number of alternatives; $j=1,2, \ldots, n ; n$ is the number of decision criteria (objectives); $\bar{x}_{i j}$ is a dimensionless value of a decision criterion.

The first part of the approach is based on the ratio system [44]. To calculate the relative significance, $\bar{y}_{i}$, of each alternative $i$ with respect to all objectives $j$, the weighted normalized criteria values should be added in the case of maximization, while, in the case of minimization, the weighted normalized criteria values should be subtracted as follows:

$$
\bar{y}_{i}=\sum_{j=1}^{j=g} \bar{x}_{i j} w_{j}-\sum_{j=g+1}^{j=n} \bar{x}_{i j} w_{j},
$$

where $j=1,2, \ldots, g$ are maximized decision criteria; $j=$ $g+1, g+2, \ldots, n$ are minimized decision criteria; $w_{j}$ is the weight (or relative significance) of a criterion.

The values of variables $\bar{y}_{i}$ show the preference of the alternatives according to the ratio system approach.

The second part of the approach is based on the maximal objective reference point [44]. First, the desirable ideal alternative should to be established. The virtual ideal alternative consists of the best values of the considered criteria $r_{j}$. It is formed by selecting the best criteria values from every decision alternative based on their optimization direction, that is, the maximal values from the criteria set $j=1,2, \ldots, g$ and the minimal values from the criteria set $j=g+1, g+$ $2, \ldots, n$.

All criteria values were transformed by applying vector normalization (1). Having the dimensionless values of the criteria $\bar{x}_{i j}$ and relative significances (weights) of the criteria $w_{j}$, decision alternatives are ranked based on the Min-Max metric of Tchebycheff [60]:

$$
\underset{(i)}{\operatorname{Min}}\left\{\max _{(j)}\left|r_{j}-\bar{x}_{i j} w_{j}\right|\right\} .
$$

The second part of the approach is based on the full multiplicative form, as presented by Brauers and Zavadskas [44]. The full multiplicative form for calculating the utility of the alternatives $U_{i}$ is applied as follows:

$$
U_{i}=\frac{A_{i}}{B_{i}}
$$

where $A_{i}$ and $B_{i}$ are calculated separately for maximized decision criteria $j=1,2, \ldots, g$ and minimized decision criteria $j=g+1, g+2, \ldots, n$, respectively. $A_{i}$ and $B_{i}$ are calculated as follows:

$$
\begin{aligned}
& A_{i}=\prod_{j=1}^{g} w_{j} \bar{x}_{i j}, \\
& B_{i}=\prod_{j=g+1}^{n} w_{j} \bar{x}_{i j} .
\end{aligned}
$$

The MULTIMOORA is based on the theory of dominance [46] and summarizes the MOORA, involving the above described ratio system and the reference point approaches, as well as the full multiplicative form [45].

Robustness of the method has been verified proving that accuracy of aggregated approaches is larger comparing to accuracy of single ones [47]. The method has been widely applied to evaluate alternatives and to select the best decisions in engineering technology or management problems by using a single approach or its combinations with other MADM methods [13, 48-50]. However, the farther the more complex 
decisions should be made and decision makers usually face a larger amount of approximate or partial information. Accordingly, extensions of conventional MADM methods under uncertain environment for group decision making are essential. The further developed IVIF-MULTIMOORA method could be applied in innovation themes in engineering, such as sustainable building life-cycle modelling and evaluating and selecting new business models to finance, build, and manage public buildings and infrastructures.

\section{Interval-Valued Intuitionistic Fuzzy Sets}

Zadeh [6] generalized the characteristic function of classic sets into membership function and introduced fuzzy sets, where a membership degree was assigned to each element of a fuzzy set. Later, Atanassov [9] proposed the idea of intuitionistic fuzzy sets (IFSs), when a nonmembership degree is assigned to each element of the set alongside its membership. The interval-valued intuitionistic fuzzy sets (IVIFSs) present an extended form of IFSs.

Let $D[0,1]$ be the set of all closed subintervals of the interval $[0,1]$ and let $X(\neq \Phi)$ be a given set. An IVIFS in $X$ was defined as $\widetilde{A}=\left\{\left\langle x, \mu_{\widetilde{A}}(x), v_{\widetilde{A}}(x)\right\rangle \mid x \in X\right\}$, where $\mu_{\widetilde{A}}: X \rightarrow D[0,1]$ and $v_{\widetilde{A}}: X \rightarrow D[0,1]$ with condition $0 \prec \sup _{x} \mu_{\widetilde{A}}(x)+\sup _{x} v_{\widetilde{A}}(x) \leq 1$. The intervals $\mu_{\widetilde{A}}(x)$ and $v_{\widetilde{A}}(x)$ denote the degree of membership and nonmembership of the element $x$ of the set $A$. Thus, for each $x \in X, \mu_{\widetilde{A}}(x)$ and $v_{\widetilde{A}}(x)$ are closed intervals whose lower and upper end points are denoted by $\mu_{A L}(x), \mu_{A U}(x), v_{A L}(x)$, and $v_{A U}(x)$.

The IVIFS was denoted by

$$
\begin{aligned}
A & =\left\{\left\langle x,\left[\mu_{A L}(x), \mu_{A U}(x)\right],\left[v_{A L}(x), v_{A U}(x)\right]\right\rangle \mid x\right. \\
& \in X\}
\end{aligned}
$$

where $0 \prec \mu_{A U}(x)+v_{A U}(x) \leq 1, \mu_{A L}(x), v_{A L}(x) \geq 0$. For convenience, the IVIFS value was denoted by $\widetilde{A}=([a, b],[c, d])$ and referred to as an interval-valued intuitionistic fuzzy number (IVIFN).

The algebraic operations were extended over IVIFSs. Let $\widetilde{A_{1}}=\left(\left[a_{1}, b_{1}\right],\left[c_{1}, d_{1}\right]\right)$ and $\widetilde{A}_{2}=\left(\left[a_{2}, b_{2}\right],\left[c_{2}, d_{2}\right]\right)$ be any two IVIFNs; then [43]

$$
\begin{aligned}
& \begin{aligned}
\widetilde{A}_{1} & +\widetilde{A}_{2} \\
& =\left(\left[a_{1}+a_{2}-a_{1} a_{2}, b_{1}+b_{2}-b_{1} b_{2}\right],\left[c_{1} c_{2}, d_{1} d_{2}\right]\right), \\
\widetilde{A}_{1} & \cdot \widetilde{A}_{2} \\
& =\left(\left[a_{1} a_{2}, b_{1} b_{2}\right],\left[c_{1}+c_{2}-c_{1} c_{2}, d_{1}+d_{2}-d_{1} d_{2}\right]\right), \\
\lambda \widetilde{A}_{1} & =\left(\left[1-\left(1-a_{1}\right)^{\lambda}, 1-\left(1-b_{1}\right)^{\lambda}\right],\left[c_{1}^{\lambda}, d_{1}^{\lambda}\right]\right),
\end{aligned}
\end{aligned}
$$

The division and subtraction operations were defined as follows, using the extension principle [61]:

$$
\begin{gathered}
\widetilde{A}_{1} \div \widetilde{A}_{2}=\left\{\left[\min \left(a_{1}, a_{2}\right), \min \left(b_{1}, b_{2}\right)\right],\right. \\
\left.\left[\max \left(c_{1}, c_{2}\right), \max \left(d_{1}, d_{2}\right)\right]\right\}, \\
\widetilde{A}_{1}-\widetilde{A}_{2}=\left\{\left[\min \left(a_{1}, a_{2}\right), \min \left(b_{1}, b_{2}\right)\right],\right. \\
\left.\left[\max \left(c_{1}, c_{2}\right), \max \left(d_{1}, d_{2}\right)\right]\right\} .
\end{gathered}
$$

Since the final rating of the alternatives is usually determined as IVIFNs, it requires their comparison. This comparison was made, using the score and accuracy functions [43]. Let $\widetilde{A}=([a, b],[c, d])$ be an IVIFN. Then,

$$
s(\widetilde{A})=\frac{1}{2}(a-c+b-d)
$$

was called the score function of $\widetilde{A}$, where $s(\widetilde{A}) \in[-1,1]$, while

$$
h(\widetilde{A})=\frac{1}{2}(a+c+b+d)
$$

was referred to as the accuracy function of $A$, where $h(\widetilde{A}) \epsilon$ $[0,1]$.

For $\widetilde{A}_{1}$ and $\widetilde{A}_{2}$ as two IVIFNs, it follows that [43]

(1) if $s\left(\widetilde{A}_{1}\right) \prec s\left(\widetilde{A}_{2}\right)$, then $\widetilde{A}_{1}$ is smaller than $\widetilde{A}_{2}, \widetilde{A}_{1} \prec$ $\widetilde{A}_{2}$;

(2) if $s\left(\widetilde{A}_{1}\right)=s\left(\widetilde{A}_{2}\right)$, then

(a) if $h\left(\widetilde{A}_{1}\right)=h\left(\widetilde{A}_{2}\right)$, then $\widetilde{A}_{1}=\widetilde{A}_{2}$,

(b) if $h\left(\widetilde{A}_{1}\right) \prec h\left(\widetilde{A}_{2}\right)$, then $\widetilde{A}_{1}$ is smaller than $\widetilde{A}_{2}$, $\widetilde{A}_{1}<\widetilde{A}_{2}$.

Another requirement of group decision making is associated with the aggregation of different judgments of decision makers into a single estimate. In this case, aggregation operators on IVIFNs can be used. Let $\widetilde{A}_{j}=$ $\left(\left[a_{j}, b_{j}\right],\left[c_{j}, d_{j}\right]\right), j=1,2, \ldots, n$, be a collection of IVIFNs. Then, the generalized interval intuitionistic fuzzy weighted average $\operatorname{GIIFWA}_{w}\left(\widetilde{A}_{1}, \widetilde{A}_{2}, \ldots, \widetilde{A}_{n}\right)$ was defined as

$$
\begin{aligned}
& \operatorname{GIIFWA}_{w}\left(A_{1}, A_{2}, \ldots, A_{n}\right) \\
& \quad=\left(w_{1} \widetilde{A}_{1}^{\lambda}+w_{2} \widetilde{A}_{2}^{\lambda}+\cdots+w_{n} \widetilde{A}_{n}^{\lambda}\right)^{1 / \lambda},
\end{aligned}
$$

where $\lambda>0$, and $w=\left(w_{1}, w_{2}, \ldots, w_{n}\right)^{T}$ is the weight vector with $w_{j} \geq 0, j=1,2, \ldots, n$, and $\sum_{j=1}^{n} w_{j}=1$. It can be shown 
that GIIFWA is also an IVIFN and can be calculated as follows [62]:

$$
\begin{aligned}
& \operatorname{GIFWA}_{w}\left(\widetilde{A}_{1}, \widetilde{A}_{2}, \ldots, \widetilde{A}_{n}\right) \\
& =\left(\left[\left(1-\prod_{j=1}^{n}\left(1-a_{j}^{\lambda}\right)^{w_{j}}\right)^{1 / \lambda},\right.\right. \\
& \left.\left(1-\prod_{j=1}^{n}\left(1-b_{j}^{\lambda}\right)^{w_{j}}\right)^{1 / \lambda}\right],[1 \\
& -\left(1-\prod_{j=1}^{n}\left(1-\left(1-c_{j}\right)^{\lambda}\right)^{w_{j}}\right)^{1 / \lambda}, 1 \\
& \left.\left.-\left(1-\prod_{j=1}^{n}\left(1-\left(1-d_{j}\right)^{\lambda}\right)^{w_{j}}\right)^{1 / \lambda}\right]\right) .
\end{aligned}
$$

If $\lambda=1$, then GIIFWA is turned into the interval intuitionistic fuzzy weighted average (IIFWA).

\section{IVIF-MULTIMOORA for Group Decision Making}

5.1. IVIF-MULTIMOORA. Assume that a group of $K$ decision makers (experts) wants to appraise a set of $m$ alternatives $A_{1}, A_{2}, \ldots, A_{m}$, based on a set of $n$ criteria $C_{1}, C_{2}, \ldots, C_{n}$. Also, the weight vector $w_{1}, w_{2}, \ldots, w_{n}$, with $w_{j} \geq 0, j=$ $1,2, \ldots, n$, and $\sum_{j=1}^{n} w_{j}=1$ is determined that shows the relative importance of different criteria on final decision. Due to incomplete and ill-defined data, the required information in the considered problem is expressed by IVIFNs.

At the first step, each decision maker expresses his/her decision matrix $\widetilde{X}^{k}, k=1,2, \ldots, K$, as follows:

$$
\widetilde{X}^{k}=\left[\begin{array}{cccc}
\tilde{x}_{11}^{k} & \tilde{x}_{12}^{k} & \cdots & \tilde{x}_{1 n}^{k} \\
\tilde{x}_{21}^{k} & \tilde{x}_{22}^{k} & \cdots & \tilde{x}_{2 n}^{k} \\
\vdots & \vdots & \cdots & \vdots \\
\tilde{x}_{m 1}^{k} & \tilde{x}_{m 2}^{k} & \cdots & \tilde{x}_{m n}^{k}
\end{array}\right],
$$

where $\tilde{x}_{i j}^{k}$ represents the IVIF performance of the alternative $A_{i}$ over the criterion $C_{j}$ from the viewpoint of $k$ th decision maker. The aim of a decision making group is to rank the alternatives.

To solve this MAGDM problem, an IVIF version of the MULTIMOORA method, called IVIF-MULTIMOORA, was extended and described in this section. Initially, the aggregation was required to transform the set of $K$ decision matrices to an aggregated decision matrix. This aggregated decision matrix had the form of $\widetilde{X}=\left[\widetilde{x}_{i j}\right]$. If an equal weight was assumed for decision makers, then

$$
\tilde{x}_{i j}=\left(\left[\mu_{i j}^{l}, \mu_{i j}^{u}\right],\left[v_{i j}^{l}, v_{i j}^{u}\right]\right)=\operatorname{IIFWA}\left(\tilde{x}_{i j}^{1}, \widetilde{x}_{i j}^{2}, \ldots, \widetilde{x}_{i j}^{K}\right) .
$$

The aggregation operation was performed using the GIIFWA operator and considering the weight vector $V=$ $\left(v_{1}, v_{2}, \ldots, v_{K}\right)$ for different decision makers.

Since the aggregated decision matrix $\widetilde{X}=\left[\widetilde{x}_{i j}\right]$ was available, the IVIF-MULTIMOORA method was proposed to solve the MAGDM problem. As mentioned in Section 3, the MULTIMOORA method involves three parts: the ratio system (1), the reference point approach (2), and the full multiplicative form (3).

5.2. The Part of MOORA Based on the IVIF-Ratio System. The first step in the ratio system is the normalization of the decision matrix. However, since IVIFNs are commensurable numbers, normalization is not required. The set of criteria was decomposed into two subsets of the benefit criteria (where more is better) and cost criteria (where less is better). Then, the $\tilde{y}_{i}, i=1,2, \ldots, m$, score of alternatives was computed by adding its weighted benefit criteria and subtracting the weighted cost criteria. If the benefit criteria were ordered as $C_{1}, C_{2}, \ldots, C_{g}$ and cost criteria as $C_{g+1}, C_{g+2}, \ldots, C_{n}$, then

$$
\tilde{y}_{i}=\sum_{j=1}^{g} w_{j} \widetilde{x}_{i j}-\sum_{j=g+1}^{n} w_{j} \widetilde{x}_{i j} .
$$

This score could be computed by applying the IVIFNs algebraic operators and the extension principle given in Section 4 . However, a slight modification could simplify the computations. Let $W^{+}=\sum_{j=1}^{g} w_{j}$ and $W^{-}=\sum_{j=g+1}^{n} w_{j}$. Then, $w_{j}^{\prime}=w_{j} / W^{+}$for each $j \in\{1,2, \ldots, g\}$, and $w_{j}^{\prime \prime}=w_{j} / W^{-}$ for each $j \in\{g+1, g+2, \ldots, n\}$. It was clear that $w_{j}^{\prime} \geq$ $0, j=1,2, \ldots, g$, and $\sum_{j=1}^{g} w_{j}^{\prime}=1$. Similarly, $w_{j}^{\prime \prime} \geq 0, j=$ $1,2, \ldots, g$, and $\sum_{j=1}^{g} w_{j}^{\prime \prime}=1$. Then,

$$
\tilde{y}_{i}^{\prime}=\frac{\tilde{y}_{i}}{W^{+} W^{-}} .
$$

Multiplying both sides of (18) by positive value of $1 /\left(W^{+} W^{-}\right),(18)$ was transformed as follows:

$$
\tilde{y}_{i}^{\prime}=\frac{1}{W^{-}} \sum_{j=1}^{g} w_{j}^{\prime} \tilde{x}_{i j}-\frac{1}{W^{+}} \sum_{j=g+1}^{n} w_{j}^{\prime \prime} \tilde{x}_{i j} .
$$

Based on the IIFWA operator definition, (18) was represented as

$$
\begin{aligned}
\tilde{y}_{i}^{\prime}= & \frac{1}{W^{-}} \operatorname{IIFWA}_{W^{+}}\left(\tilde{x}_{i 1}, \tilde{x}_{i 2}, \ldots, \tilde{x}_{i g}\right) \\
& -\frac{1}{W^{+}} \operatorname{IIFWA}_{W^{-}}\left(\tilde{x}_{i g+1}, \tilde{x}_{i g+2}, \ldots, \tilde{x}_{i n}\right) .
\end{aligned}
$$

The multiplication of $1 /\left(W^{-}\right)$and $1 /\left(W^{+}\right)$was performed using (9). In addition, the subtraction of two IVIFNs in (21) was performed by applying (16). $\tilde{y}_{i}^{\prime}, i=1,2, \ldots, m$, is relative significance of the alternative $i$. The comparison of $\tilde{y}_{i}^{\prime}, i=1,2, \ldots, m$, values based on the score and the accuracy function resulted in the ranking of the alternatives based on the ratio system. 
5.3. The IVIF-Reference Point Portion of the MOORA Method. According to the second part of the MOORA, the maximal objective reference point approach was used. The desirable ideal alternative in the IVIF environment was the IVIF vector with the coordinates $\widetilde{r}_{j}, j=1,2, \ldots, n$, which was formed by selecting the data from every considered decision alternative and taking into account the optimization direction of every particular criterion. To find the reference point based on the idea of the TOPSIS method, the weighted decision matrix $\widetilde{N}=\left[\widetilde{n}_{i j}\right]=W \cdot \widetilde{X}$ was constructed first, where

$$
\tilde{n}_{i j}=\left(\left[\eta_{i j}^{l}, \eta_{i j}^{u}\right],\left[\delta_{i j}^{l}, \delta_{i j}^{u}\right]\right)=w_{j} \tilde{x}_{i j}
$$

The scalar multiplication was performed by applying (9). Then, for benefit criteria, $C_{1}, C_{2}, \ldots, C_{g}$, the reference point was constructed as follows:

$$
\begin{aligned}
\tilde{r}_{j} & =\left(\left[\eta_{i j}^{* l}, \eta_{i j}^{* u}\right],\left[\delta_{i j}^{* l}, \delta_{i j}^{* u}\right]\right) \\
& =\left(\left[\max _{1 \leq i \leq m}\left(\eta_{i j}^{l}\right), \max _{1 \leq i \leq m}\left(\eta_{i j}^{u}\right)\right],\right. \\
& {\left.\left[\min _{1 \leq i \leq m}\left(\delta_{i j}^{l}\right), \min _{1 \leq i \leq m}\left(\delta_{i j}^{u}\right)\right]\right), }
\end{aligned}
$$

and for cost criteria, $C_{g+1}, C_{g+2}, \ldots, C_{n}$,

$$
\begin{aligned}
\tilde{r}_{j} & =\left(\left[\eta_{i j}^{* l}, \eta_{i j}^{* u}\right],\left[\delta_{i j}^{* l}, \delta_{i j}^{* u}\right]\right) \\
& =\left(\left[\min _{1 \leq i \leq m}\left(\mu_{i j}^{l}\right), \min _{1 \leq i \leq m}\left(\mu_{i j}^{u}\right)\right],\right. \\
& {\left.\left[\max _{1 \leq i \leq m}\left(v_{i j}^{l}\right), \max _{1 \leq i \leq m}\left(v_{i j}^{u}\right)\right]\right) . }
\end{aligned}
$$

Then, the Min-Max metric of Tchebycheff [26] was used for ranking the alternatives:

$$
\operatorname{Min}_{1 \leq i \leq m}\left\{\max _{1 \leq j \leq n}\left|\tilde{r}_{j}-\tilde{x}_{i j} w_{j}\right|\right\} .
$$

Based on (22)-(24), (25) could be simplified. The following steps were taken to determine the rankings of the alternatives, using the reference point approach.

Step 1. Compute for each alternative $A_{i}, i=1,2, \ldots, m$, the score function in the weighted decision matrix:

$$
S\left(\widetilde{n}_{i j}\right)=\eta_{i j}^{l}-\delta_{i j}^{l}+\eta_{i j}^{u}-\delta_{i j}^{u}
$$

Step 2. Compute the score function of the reference points:

$$
S\left(\tilde{r}_{j}\right)=\eta_{i j}^{* l}-\delta_{i j}^{* l}+\eta_{i j}^{* u}-\delta_{i j}^{* u} .
$$

Step 3. Find the maximum deviation from the reference points:

$$
d_{i}=\max _{1 \leq j \leq n}\left|\widetilde{r}_{j}-\tilde{x}_{i j} w_{j}\right|=\max _{1 \leq j \leq n}\left|S\left(\widetilde{r}_{j}\right)-S\left(\tilde{n}_{i j}\right)\right|
$$

Step 4. Rank the alternatives in the ascending order of $d_{i}, i=$ $1,2, \ldots, m$.
5.4. The IVIF-Full Multiplicative Form. Finally, the full multiplicative form was applied as follows:

$$
\widetilde{U}_{i}=\frac{\widetilde{A}_{i}}{\widetilde{B}_{i}}
$$

where $\widetilde{U}_{i}$ denotes the overall utility of the alternative $i$, and

$$
\begin{aligned}
& \widetilde{A}_{i}=\prod_{j=1}^{g} w_{j} \tilde{x}_{i j}, \\
& \widetilde{B}_{i}=\prod_{j=g+1}^{n} w_{j} \tilde{x}_{i j} .
\end{aligned}
$$

Multiplication of a set of IVIFNs was performed by sequentially applying (8). To give a compact form of this multiplication, it was supposed that $\tilde{x}_{i j}, j=1,2, \ldots, g$, was determined as an IVIFN as indicated in (17). First, $\tilde{n}_{i j}=$ $w_{j} \tilde{x}_{i j}, j=1,2, \ldots, g$, was formed by applying (9) in the same manner as previously performed in (22). Then,

$$
\begin{aligned}
& \widetilde{A}_{i}=\prod_{j=1}^{g} \widetilde{n}_{i j}=\left(\left[\underline{\eta}_{i j}^{l}, \bar{\eta}_{i j}^{l}\right],\left[\underline{\delta}_{i j}^{l}, \bar{\delta}_{i j}^{u}\right]\right) \\
& =\left(\left[\prod_{j=1}^{g} \eta_{i j}^{l}, \prod_{j=1}^{g} \eta_{i j}^{u}\right],\left[\sum_{j=1}^{g} \delta_{i j}^{l}-\sum_{\substack{j_{1}<j_{2} \\
j_{1}, j_{2} \in\{1,2, \ldots, g\}}} \delta_{i j_{1}}^{l} \cdot \delta_{i j_{2}}^{l}\right.\right. \\
& +\cdots+(-1)^{k+1} \sum_{\substack{j_{1}<j_{2}<\cdots<j_{k} \\
j_{1}, j_{2}, \ldots, j_{k} \in\{1,2, \ldots, g\}}}\left(\delta_{i j_{1}}^{l} \cdot \delta_{i j_{2}}^{l} \cdots \delta_{i j_{k}}^{l}\right)+\cdots \\
& +(-1)^{g+1}\left(\delta_{i 1}^{l} \cdot \delta_{i 2}^{l} \cdots \delta_{i g}^{l}\right), \sum_{j=1}^{g} \delta_{i j}^{u} \\
& -\sum_{\substack{j_{1}<j_{2} \\
j_{1}, j_{2} \in\{1,2, \ldots, g\}}} \delta_{i j_{1}}^{u} \cdot \delta_{i j_{2}}^{u}+\cdots \\
& +(-1)^{k+1} \sum_{\substack{j_{1}<j_{2}<\cdots<j_{k} \\
j_{1}, j_{2}, \cdots, j_{k} \in\{1,2, \ldots, g\}}}\left(\delta_{i j_{1}}^{u} \cdot \delta_{i j_{2}}^{u} \cdots \delta_{i j_{k}}^{u}\right)+\cdots \\
& \left.\left.+(-1)^{g+1}\left(\delta_{i 1}^{u} \cdot \delta_{i 2}^{u} \cdots \delta_{i g}^{u}\right)\right]\right)
\end{aligned}
$$

Then $\widetilde{B}_{i}, i=1,2, \ldots, m$, was also calculated in a similar way. Then, $\widetilde{U}_{i}, i=1,2, \ldots, m$, was determined by (10) for division. The ranking of the alternatives was specified by calculating the score functions $S\left(\widetilde{U}_{i}\right), i=1,2, \ldots, m$, and ranking them in a descending order.

Applying three distinct parts of MULTIMOORA, three sets of rankings of the alternatives were determined. The obtained rankings formed a ranking pool, based on which the final ranking of the alternatives could be determined. To find 


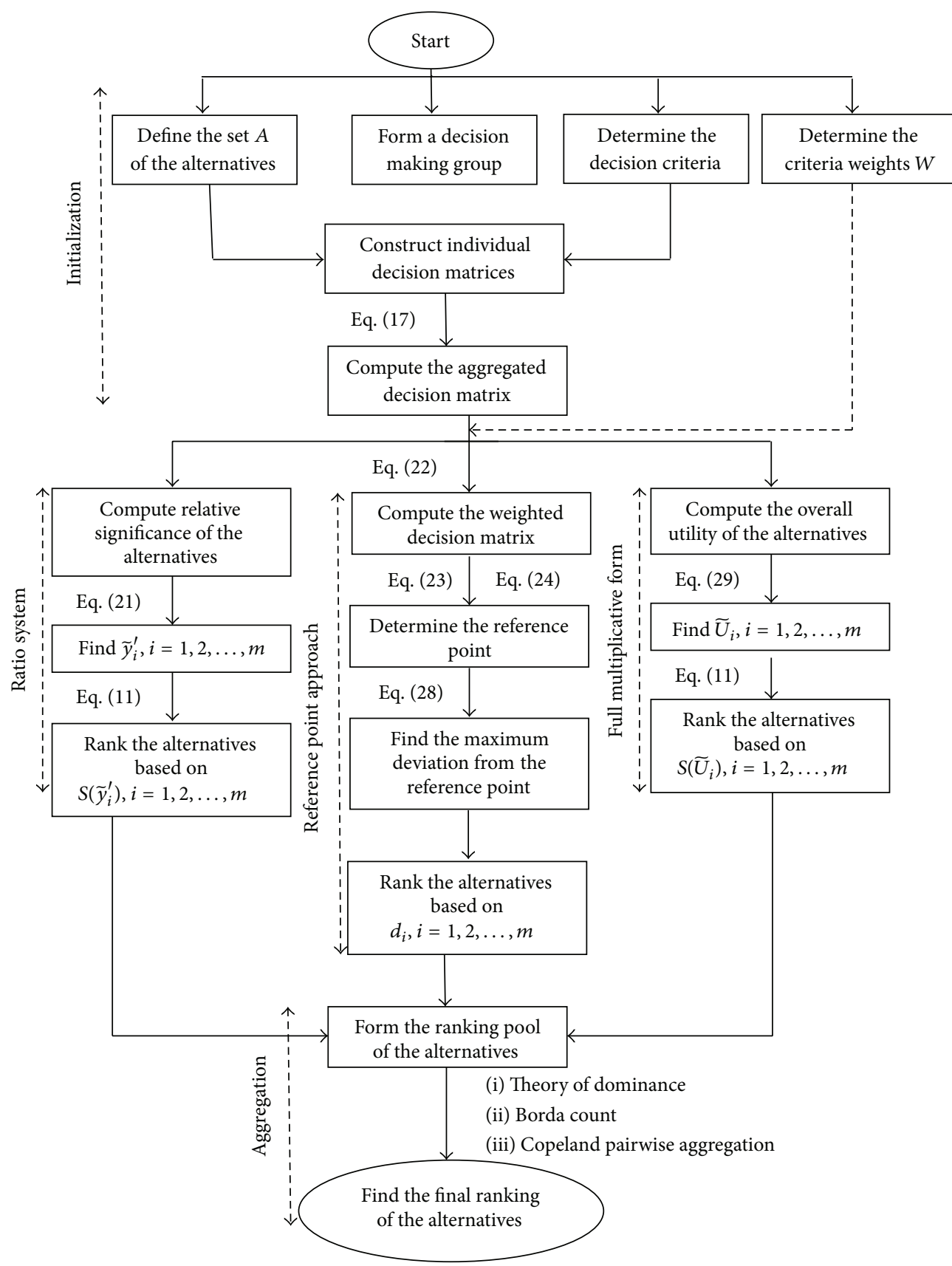

FIGURE 1: The IVIF-MULTIMOORA algorithm.

the final ranking of the alternatives, the theory of dominance [46] could be used. Also, the techniques, such as the Borda count method [63] or Copeland pairwise aggregation method [64], could be applied to determine the final ranking of the alternatives.

5.5. The IVIF-MULTIMOORA Algorithm. MULTIMOORA is the extension of the MOORA method and the full multiplicative form of multiple-objective. The distinct parts of the MULTIMOORA method are presented in Sections 5.1 to 5.3. The algorithmic scheme of MULTIMOORA is presented in the current section. The IVIF-MULTIMOORA algorithm includes five different stages: (1) initialization, (2) IVIFratio system, (3) IVIF-reference point approach, (4) IVIF-full multiplicative form, and (5) final ranking. These stages are presented in Figure 1.

\section{A Numerical Example}

In this section, two applications of the proposed method are presented and the results are compared to the rankings yielded by other multiple criteria decision making methods. 
TABLE 1: Decision matrix of rational revitalization of derelict and mismanaged buildings.

\begin{tabular}{lccccc}
\hline Criteria & Optimization direction & Weight & $A_{1}$ & $A_{2}$ & $A_{3}$ \\
$\tilde{x}_{1}$ & $\operatorname{Max}$ & 0.0600 & $([0.70,0.80],[0.10,0.15])$ & $([0.45,0.60],[0.20,0.30])$ & $([0.30,0.40],[0.45,0.50])$ \\
$\tilde{x}_{2}$ & $\operatorname{Min}$ & 0.0727 & $([0.60,0.70],[0.15,0.20])$ & $([0.45,0.55],[0.20,0.30])$ & $([0.25,0.40],[0.45,0.55])$ \\
$\tilde{x}_{3}$ & $\operatorname{Max}$ & 0.0747 & $([0.75,0.80],[0.10,0.15])$ & $([0.45,0.55],[0.25,0.35])$ & $([0.30,0.40],[0.40,0.50])$ \\
$\tilde{x}_{4}$ & $\operatorname{Max}$ & 0.0627 & $([0.80,0.90],[0,0.05])$ & $([0.50,0.65],[0.15,0.25])$ & $([0.35,0.50],[0.30,0.40])$ \\
$\tilde{x}_{5}$ & $\operatorname{Max}$ & 0.0673 & $([0.70,0.85],[0.05,0.10])$ & $([0.55,0.65],[0.20,0.25])$ & $([0.35,0.45],[0.30,0.40])$ \\
$\tilde{x}_{6}$ & $\operatorname{Max}$ & 0.0627 & $([0.75,0.85],[0.10,0.15])$ & $([0.55,0.65],[0.20,0.25])$ & $([0.35,0.45],[0.30,0.40])$ \\
$\tilde{x}_{7}$ & $\operatorname{Min}$ & 0.0667 & $([0.80,0.85],[0.10,0.15])$ & $([0.45,0.55],[0.25,0.35])$ & $([0.15,0.35],[0.40,0.50])$ \\
$\tilde{x}_{8}$ & $\operatorname{Max}$ & 0.0667 & $([0.85,0.90],[0,0.05])$ & $([0.20,0.35],[0.35,0.50])$ & $([0.10,0.15],[0.75,0.80])$ \\
$\tilde{x}_{9}$ & $\operatorname{Max}$ & 0.0667 & $([0.80,0.90],[0,0.05])$ & $([0.10,0.25],[0.55,0.65])$ & $([0.05,0.10],[0.80,0.85])$ \\
$\tilde{x}_{10}$ & $\operatorname{Max}$ & 0.0667 & $([0.45,0.60],[0.25,0.35])$ & $([0.10,0.25],[0.55,0.65])$ & $([0.05,0.10],[0.80,0.85])$ \\
$\tilde{x}_{11}$ & $\operatorname{Max}$ & 0.0667 & $([0.75,0.80],[0.10,0.15])$ & $([0.15,0.30],[0.30,0.50])$ & $([0.05,0.10],[0.75,0.85])$ \\
$\tilde{x}_{12}$ & $\operatorname{Max}$ & 0.0667 & $([0.75,0.85],[0.05,0.10])$ & $([0.25,0.40],[0.20,0.40])$ & $([0.70,0.80],[0.10,0.15])$ \\
$\tilde{x}_{13}$ & $\operatorname{Min}$ & 0.0667 & $([0.70,0.85],[0.05,0.10])$ & $([0.10,0.15],[0.75,0.80])$ & $([0.50,0.55],[0.35,0.40])$ \\
$\tilde{x}_{14}$ & $\operatorname{Min}$ & 0.0667 & $([0.70,0.80],[0.10,0.15])$ & $([0.50,0.55],[0.30,0.40])$ & $([0.10,0.15],[0.70,0.80])$ \\
$\tilde{x}_{15}$ & $\operatorname{Max}$ & 0.0667 & $([0.60,0.75],[0.15,0.20])$ & $([0.45,0.60],[0.20,0.30])$ & $([0.25,0.45],[0.25,0.40])$ \\
\hline
\end{tabular}

6.1. The First Example. Zavadskas et al. [36] solved a problem of rational revitalization of derelict and mismanaged buildings in Lithuanian rural areas. Three alternatives included the reconstruction of rural buildings and their adaptation to production (or commercial) activities $\left(A_{1}\right)$, as well as their improvement and use for farming $\left(A_{2}\right)$ or dismantling and recycling the demolition waste materials $\left(A_{3}\right)$. The following criteria were taken into consideration: the average soil fertility in the area $x_{1}$ (points), quality of life of the local population $x_{2}$ (points), population activity index $x_{3}(\%)$, GDP proportion with respect to the average GDP of the country $x_{4}(\%)$, material investment in the area $x_{5}$ (LTL per resident), foreign investments in the area $x_{6}\left(\mathrm{LTL} \times 10^{3}\right.$ per resident), building redevelopment costs $x_{7}\left(\mathrm{LTL} \times 10^{6}\right)$, increase in the local population's income $x_{8}$ (LTL $\times 10^{6}$ per year), increase in sales in the area $x_{9}(\%)$, increase in employment in the area $x_{10}(\%)$, state income from business and property taxes $x_{11}\left(\mathrm{LTL} \times 10^{6}\right.$ per year), business outlook $x_{12}$, difficulties in changing the original purpose of the site $x_{13}$, the degree of contamination $x_{14}$, and the attractiveness of the countryside (i.e., image and landscape) $x_{15}$.

A decision matrix is presented in Table 1.

This problem was solved with the proposed IVIFMULTIMOORA method as follows.

6.1.1. Ratio System. In the ratio system ranking, the relative importance (significance) of the alternatives was determined by (21). For this purpose, initially, the benefit criteria, including $x_{1}, x_{2}, x_{3}, x_{4}, x_{5}, x_{6}, x_{8}, x_{9}, x_{10}, x_{11}, x_{12}$, and $x_{15}$, were separated from the cost criteria, including $x_{7}, x_{13}$, and $x_{14}$. Then, the aggregations of the benefit criteria weights, $W^{+}$, and cost criteria weights, $W^{-}$, were computed. These weights were then used in (21), and the values of $\tilde{y}_{i}^{\prime}, i=1,2,3$, were calculated as follows:

$$
\tilde{y}_{1}^{\prime}=([0.285,0.363],[0.531,0.602]),
$$

$$
\begin{aligned}
& \tilde{y}_{2}^{\prime}=([0.110,0.136],[0.787,0.833]), \\
& \tilde{y}_{3}^{\prime}=([0.077,0.110],[0.824,0.858])
\end{aligned}
$$

Ranking these values according to their score functions led to the ranking of the alternatives as $A_{1}>A_{2}>A_{3}$.

6.1.2. Reference Point Approach. Ranking of the alternatives in this approach was initialized by determining a reference point from the weighted decision matrix. Then, the deviation of each alternative from the reference point was computed by (28). These deviations were as follows: $d_{1}=0.468, d_{2}=1.332$, and $d_{3}=1.391$. By ranking the alternatives in the descending order of deviations, the final ranking was determined as $A_{1}>$ $A_{2}>A_{3}$.

6.1.3. Full Multiplicative Form. In applying the third part of the method, the full multiplicative approach was used to rank the alternatives. Using (30), the multiplicative forms of benefit and cost criteria were obtained. These multiplicative forms were constructed by sequential multiplication of a set of IVIFNs. The overall utility of the alternatives was determined as follows:

$$
\begin{aligned}
\widetilde{U}_{1} & =([6.010 E-14,2.028 E-12],[9.999999825 E \\
& -1,9.9999999998 E-1]), \\
\widetilde{U}_{2} & =([4.127 E-20,2.310 E-17],
\end{aligned}
$$

[9.99999999999909E-1, 9.999999999999998E

$$
-1])
$$

$\widetilde{U}_{3}=([0,0],[1,1])$.

Ranking these values according to their score functions led to ranking of the alternatives as $A_{1}>A_{2}>A_{3}$. 
TABLE 2: IVIF-MULTIMOORA ranking of the alternatives.

\begin{tabular}{lcccc}
\hline Alternatives & IVIF-MOORA ratio system & IVIF-MOORA reference point & IVIF-full multiplicative form & IVIF-MULTIMOORA \\
\hline$A_{1}$ & 1 & 1 & 1 & 1 \\
$A_{2}$ & 2 & 2 & 2 & 2 \\
$A_{3}$ & 3 & 3 & 3 & 3 \\
\hline
\end{tabular}

TABLE 3: Ranking of the alternatives by applying different methods.

\begin{tabular}{lccccc}
\hline Alternatives & IFOWA & TOPSIS-IVIF & COPRAS-IVIF & WASPAS-IVIF & IVIF-MULTIMOORA \\
\hline$A_{1}$ & 1 & 1 & 1 & 1 & 1 \\
$A_{2}$ & 2 & 2 & 3 & 2 & 2 \\
$A_{3}$ & 3 & 3 & 2 & 3 & 3 \\
\hline
\end{tabular}

TABLE 4: IVIF decision matrix for investment alternatives.

\begin{tabular}{ccccc}
\hline & $C_{1}$ & $C_{2}$ & $C_{3}$ & $C_{4}$ \\
\hline$A_{1}$ & $([0.42,0.48],[0.4,0.5])$ & $([0.6,0.7],[0.05,0.025])$ & $([0.4,0.5],[0.2,0.5])$ & $([0.55,0.75],[0.15,0.25])$ \\
$A_{2}$ & $([0.4,0.5],[0.4,0.5])$ & $([0.5,0.8],[0.1,0.2])$ & $([0.3,0.6],[0.3,0.4])$ & $([0.6,0.7],[0.1,0.3])$ \\
$A_{3}$ & $([0.3,0.5],[0.4,0.5])$ & $([0.1,0.3],[0.2,0.4])$ & $([0.7,0.8],[0.1,0.2])$ & $([0.5,0.7],[0.1,0.2])$ \\
$A_{4}$ & $([0.2,0.4],[0.4,0.5])$ & $([0.6,0.7],[0.2,0.3])$ & $([0.5,0.6],[0.2,0.3])$ & $([0.7,0.8],[0.1,0.2])$ \\
\hline
\end{tabular}

TABLE 5: IVIF-MULTIMOORA ranking of the investment alternatives.

\begin{tabular}{lcccc}
\hline Alternatives & IVIF-MOORA ratio system & IVIF-MOORA reference point & IVIF-full multiplicative form & IVIF-MULTIMOORA \\
\hline$A_{1}$ & 3 & 2 & 3 & 3 \\
$A_{2}$ & 4 & 1 & 4 & 4 \\
$A_{3}$ & 1 & 4 & 1 & 1 \\
$A_{4}$ & 2 & 3 & 2 & 2 \\
\hline
\end{tabular}

TABLE 6: Ranking of the investment alternatives by applying different methods.

\begin{tabular}{lcccccc}
\hline Alternatives & Wang et al. & IFOWA & TOPSIS-IVIF & COPRAS-IVIF & WASPAS-IVIF & IVIF-MULTIMOORA \\
\hline$A_{1}$ & 3 & 4 & 2 & 3 & 3 & 4 \\
$A_{2}$ & 4 & 3 & 4 & 4 & 2 & 4 \\
$A_{3}$ & 2 & 1 & 1 & 1 & 2 & 1 \\
$A_{4}$ & 1 & 2 & 3 & 2 & 2 \\
\hline
\end{tabular}

The three sets of rankings are summarized in Table 2. The final ranking was obtained by using the dominance theory in the last column of the table.

Table 3 also presents the rankings obtained by some different methods, including IFOWA [62], TOPSIS-IVIF [19], COPRAS-IVIF [31], and WASPAS-IVIF [36].

Kendall's coefficient of concordance in Table 3 is 0.840 , which shows a high degree of concordance. Moreover, there is complete coincidence among the IVIF-MULTIMOORA method and the other three methods. These facts imply that there is great homogeneity between IVIF-MULTIMOORA and other methods.

6.2. The Second Example. Consider the problem of appraising four different investment alternatives $\left\{A_{1}, A_{2}, A_{3}, A_{4}\right\}$ based on four criteria of risk $\left(C_{1}\right)$, growth $\left(C_{2}\right)$, sociopolitical issues $\left(C_{3}\right)$, and environmental impacts $\left(C_{4}\right)$. The vector of criteria significance is $(0.13,0.17,0.39,0.31)$. Also, $C_{1}$ and $C_{3}$ were considered as cost criteria, while $C_{2}$ and $C_{4}$ were benefit criteria. The problem was initially formulated by Wang et al. [51] as the decision matrix which is given below (Table 4).

The above problem was solved by using the proposed IVIF-MULTIMOORA method. The results obtained by using the ratio system, the reference point approach, and the full multiplicative form are presented in Table 5. Moreover, the final ranking obtained based on the dominance theory is presented in the last column of the table.

The results obtained by solving the above problem by different methods, including the method of Wang et al. [51], IFOWA [62], TOPSIS-IVIF [19], COPRAS-IVIF [31], and WASPAS-IVIF [36], are presented in Table 6.

In this case, Kendall's coefficient of concordance is 0.766 , which shows a high degree of concordance, compared to the critical value of 0.421 [65]. Spearman's rank correlation is used to demonstrate the similarity between different rankings. Table 7 shows Spearman's rank correlation between the 
TABLE 7: Ranking similarity of the investment alternatives by applying different methods.

\begin{tabular}{lcccccc}
\hline Methods & Wang et al. & IFOWA & TOPSIS-IVIF & CORAS-IVIF & WASPAS-IVIF & IVIF-MULTIMOORA \\
\hline Wang et al. [51] & - & $0.6(0 \%)$ & $0.4(25 \%)$ & $1(100 \%)$ & $0.8(50 \%)$ & $0.8(50 \%)$ \\
IFOWA & & - & $0.4(25 \%)$ & $0.6(0 \%)$ & $0.8(50 \%)$ & $0.8(50 \%)$ \\
TOPSIS-IVIF & & - & $0.4(25 \%)$ & $0.8(50 \%)$ & $0.8(50 \%)$ \\
CORAS-IVIF & & & - & & $0.8(50 \%)$ & $0.8(50 \%)$ \\
WASPAS-IVIF & & & & & - & - \\
IVIF-MULTIMOORA & & & & & & - \\
\hline
\end{tabular}

considered methods. The percentages specified in parenthesis in Table 7 show the matched ranks obtained by using the considered five methods with ranks of Wang et al. [51] method as the percentages of the matched alternatives.

Based on the above findings, it can be concluded that, except for COPRAS-IVIF, which completely matches the method of Wang et al. [51], the IVIF-MULTIMOORA, along with WASPAS-IVIF, has the highest similarity (reaching $80 \%)$ to all other methods. Moreover, the percentage of the matched rankings with those of Wang, $\mathrm{Li}$, and Wang is $50 \%$, which is the second high value of congruence. These results have shown great similarity of IVIF-MULTIMOORA to other methods, which can be considered to be one of its advantages.

\section{Discussion}

Vincke [66] believes that the main difficulty in solving multiple criteria decision making problems lies in the fact that, usually, there is no optimal solution to such a problem, which could dominate other solutions in all the criteria.

As a response to this dilemma, various methods have been proposed for solving MCDM problems. The selection of the most appropriate and the most robustly and effectively useable method is a continuous object of scientific discussions for decades $[67,68]$.

This means that the experts usually look for Pareto optimal solution. Therefore, while an optimal solution is obtained by several methods, this emphasizes that proposed method will achieve the near to optimum answer. In this regard, MULTIMOORA method has a strong advantage over the other methods as it summarizes three approaches. The robustness of the aggregated approach has been substantiated in the previous research [47].

On the other hand, the above-mentioned difficulty may be considered from two additional perspectives. First, the uncertainty of decision maker in his judgments should be taken into consideration. To deal with this challenge, several frameworks have been introduced, starting from application of Zadeh fuzzy numbers [6] and followed by numerous extensions of decision making methods using type 1 and type 2 fuzzy sets, involving interval-valued as well as intuitionistic fuzzy sets [69]. The extensions of the considered MULTIMOORA method till 2013 were summarized in a review paper [13]. The most recent extensions not covered by [13] should also be mentioned [14-17]. Seeking the best imagination of uncertainty, another up-to-date extension, namely, the interval-valued intuitionistic fuzzy MULTIMOORA method is presented in the current research.

Second, decisions are usually made by several decision makers. This makes it necessary to consider a suitable procedure to aggregate the opinions. Therefore, this problem is handled as a group decision making problem.

As it is not easy to prove that a newly proposed method is applicable, it is useful to test it in solving several multiple criteria problems. To make sure that the method is better or at least it is not worse than the other existing methods, it is appropriate to apply several related approaches to compare their ranking results for the same problem [70]. Accordingly, two illustrative examples have been presented to fulfill the task. It is encouraging that the results have shown great similarity of IVIF-MULTIMOORA to other methods. The fact can be considered to be one of advantages of the novel approach.

\section{Conclusions and Future Work}

In the current paper, the interval-valued intuitionistic fuzzy MULTIMOORA method is proposed for solving a group decision making problem under uncertainty. The IVIF is a generalized form of fuzzy sets which considers the nonmembership of objects in a set beside their membership and with respect to hesitancy of decision makers.

The MULTIMOORA method is a decision making procedure composed of three parts, including the ratio system, the reference point approach, and full multiplicative form. The rankings yielded by this method are finally aggregated, and a unique ranking is determined.

The proposed algorithm benefits from the abilities of IVIFSs to be used in imagination of uncertainty and MULTIMOORA method to consider three different viewpoints in analyzing decision alternatives. The application of the proposed method is illustrated by two numerical examples and the obtained results are compared to the results yielded by other methods of decision making with IVIF information. The comparison, using Kendall coefficient of concordance and Spearman's rank correlation, has shown a high consistency between the proposed method and the other approaches that verifies the proposed method can be applied in case of similar problems in ambiguous and uncertain situation. This advantage strengthens the applicability of IVIFMULTIMOORA as a method for group decision making 
under uncertainty when solving engineering technology and management complex problems.

Future directions of the research will be focused on searching modifications of the method, the best reflecting uncertain environment, and producing the most reliable results. At the moment two novel and up-to-date possible extensions of the MULTIMOORA method could be suggested. One of the approaches could be based on the neutrosophic sets $[71,72]$ that are a generalization of the fuzzy and intuitionistic fuzzy sets. The other possible approach could be to apply $D$ numbers that were recently proposed to handle uncertain information $[73,74]$.

\section{Conflict of Interests}

The authors declare that there is no conflict of interests regarding the publication of this paper.

\section{References}

[1] M. Zeleny, Multiple Criteria Decision Making, McGraw-Hill, New York, NY, USA, 1982.

[2] H. A. Simon, Models of Discovery and Other Topics in the Methods of Science, D. Reidel, Boston, Mass, USA, 1977.

[3] P. L. Yu, Forming Winning Strategies: An Integrated Theory of Habitual Domains, Springer, Heidelberg, Germany, 1990.

[4] M. C. Yovits, Advances in Computers, Academic Press, Orlando, Fla, USA, 1984.

[5] S. F. Liu and Y. Lin, Grey Systems Theory and Application, Springer, Heidelberg, Germany, 2011.

[6] L. A. Zadeh, "Fuzzy sets," Information and Computation, vol. 8, no. 3, pp. 338-353, 1965.

[7] W. Pedrycz and F. Gomide, An Introduction to Fuzzy Sets: Analysis and Design, MIT Press, Cambridge, UK, 1998.

[8] I. Grattan-Guinness, "Fuzzy membership mapped onto intervals and many-valued quantities," Mathematical Logic Quarterly, vol. 22, no. 2, pp. 149-160, 1976.

[9] K. T. Atanassov, "Intuitionistic fuzzy sets," Fuzzy Sets and Systems, vol. 20, no. 1, pp. 87-96, 1986.

[10] K. Atanassov and G. Gargov, "Interval valued intuitionistic fuzzy sets," Fuzzy Sets and Systems, vol. 31, no. 3, pp. 343-349, 1989.

[11] T. Baležentis and S. Zeng, "Group multi-criteria decision making based upon interval-valued fuzzy numbers: an extension of the MULTIMOORA method," Expert Systems with Applications, vol. 40, no. 2, pp. 543-550, 2013.

[12] T. Baležentis, S. Z. Zeng, and A. Baležentis, "MULTiMOORAIFN: a MCDM method based on intuitionistic fuzzy number for performance management," Economic Computation and Economic Cybernetics Studies and Research, vol. 48, no. 4, pp. 85-102, 2014.

[13] T. Baležentis and A. Baležentis, "A survey on development and applications of the multi-criteria decision making method MULTIMOORA," Journal of Multi-Criteria Decision Analysis, vol. 21, no. 3-4, pp. 209-222, 2014.

[14] H. Liu, X. Fan, P. Li, and Y. Chen, "Evaluating the risk of failure modes with extended MULTIMOORA method under fuzzy environment," Engineering Applications of Artificial Intelligence, vol. 34, pp. 168-177, 2014.
[15] H. Liu, J. X. You, Ch. Lu, and Y. Z. Chen, "Evaluating healthcare waste treatment technologies using a hybrid multi-criteria decision making model," Renewable and Sustainable Energy Reviews, vol. 41, pp. 932-942, 2015.

[16] H. Liu, J. X. You, C. Lu, and M. M. Shan, "Application of interval 2-tuple linguistic MULTIMOORA method for healthcare waste treatment technology evaluation and selection," Waste Management, vol. 34, no. 11, pp. 2355-2364, 2014.

[17] Z. H. Li, "An extension of the MULTIMOORA method for multiple criteria group decision making based upon hesitant fuzzy sets," Journal of Applied Mathematics, vol. 2014, Article ID 527836, 16 pages, 2014.

[18] A. K. Verma, R. Verma, and N. C. Mahanti, "Facility location selection: an interval valued intuitionistic fuzzy TOPSIS approach," Journal of Modern Mathematics and Statistics, vol. 4, no. 2, pp. 68-72, 2010.

[19] F. Ye, "An extended TOPSIS method with interval-valued intuitionistic fuzzy numbers for virtual enterprise partner selection," Expert Systems with Applications, vol. 37, no. 10, pp. 7050-7055, 2010.

[20] J. H. Park, I. Y. Park, Y. C. Kwun, and X. Tan, "Extension of the TOPSIS method for decision making problems under intervalvalued intuitionistic fuzzy environment," Applied Mathematical Modelling, vol. 35, no. 5, pp. 2544-2556, 2011.

[21] D.-F. Li, “TOPSIS-based nonlinear-programming methodology for multiattribute decision making with interval-valued intuitionistic fuzzy sets," IEEE Transactions on Fuzzy Systems, vol. 18, no. 2, pp. 299-311, 2010.

[22] D.-F. Li, "Linear programming method for MADM with interval-valued intuitionistic fuzzy sets," Expert Systems with Applications, vol. 37, no. 8, pp. 5939-5945, 2010.

[23] J. H. Park, H. J. Cho, and Y. C. Kwun, "Extension of the VIKOR method for group decision making with intervalvalued intuitionistic fuzzy information," Fuzzy Optimization and Decision Making, vol. 10, no. 3, pp. 233-253, 2011.

[24] D.-F. Li, "Closeness coefficient based nonlinear programming method for interval-valued intuitionistic fuzzy multiattribute decision making with incomplete preference information," Applied Soft Computing Journal, vol. 11, no. 4, pp. 3402-3418, 2011.

[25] S.-M. Chen, L.-W. Lee, H.-C. Liu, and S.-W. Yang, "Multiattribute decision making based on interval-valued intuitionistic fuzzy values," Expert Systems with Applications, vol. 39, no. 12, pp. 10343-10351, 2012.

[26] D. Yu, Y. Wu, and T. Lu, "Interval-valued intuitionistic fuzzy prioritized operators and their application in group decision making," Knowledge-Based Systems, vol. 30, pp. 57-66, 2012.

[27] H. Zhang and L. Yu, "MADM method based on cross-entropy and extended TOPSIS with interval-valued intuitionistic fuzzy sets," Knowledge-Based Systems, vol. 30, pp. 115-120, 2012.

[28] J. Ye, "Interval-valued intuitionistic fuzzy cosine similarity measures for multiple attribute decision-making," International Journal of General Systems, vol. 42, no. 8, pp. 883-891, 2013.

[29] F. Meng, Q. Zhang, and H. Cheng, "Approaches to multiplecriteria group decision making based on interval-valued intuitionistic fuzzy Choquet integral with respect to the generalized $\lambda$-Shapley index," Knowledge-Based Systems, vol. 37, pp. 237249, 2013.

[30] F. Meng, C. Tan, and Q. Zhang, "The induced generalized interval-valued intuitionistic fuzzy hybrid Shapley averaging operator and its application in decision making," KnowledgeBased Systems, vol. 42, pp. 9-19, 2013. 
[31] S. H. Razavi Hajiagha, S. S. Hashemi, and E. K. Zavadskas, "A complex proportional assessment method for group decision making in an interval-valued intuitionistic fuzzy environment," Technological and Economic Development of Economy, vol. 19, no. 1, pp. 22-37, 2013.

[32] J. Chai, J. N. K. Liu, and Z. Xu, "A rule-based group decision model for warehouse evaluation under interval-valued Intuitionistic fuzzy environments," Expert Systems with Applications, vol. 40, no. 6, pp. 1959-1970, 2013.

[33] S. Wan and J. Dong, "A possibility degree method for intervalvalued intuitionistic fuzzy multi-attribute group decision making," Journal of Computer and System Sciences, vol. 80, no. 1, pp. 237-256, 2014.

[34] T.-Y. Chen, "The extended linear assignment method for multiple criteria decision analysis based on interval-valued intuitionistic fuzzy sets," Applied Mathematical Modelling, vol. 38, no. 7-8, pp. 2101-2117, 2014.

[35] J. Xu and F. Shen, "A new outranking choice method for group decision making under Atanassov's interval-valued intuitionistic fuzzy environment," Knowledge-Based Systems, vol. 70, pp. 177-188, 2014.

[36] E. K. Zavadskas, J. Antucheviciene, S. H. R. Hajiagha, and S. S. Hashemi, "Extension of weighted aggregated sum product assessment with interval-valued intuitionistic fuzzy numbers (WASPAS-IVIF)," Applied Soft Computing, vol. 24, pp. 10131021, 2014.

[37] S. Geetha, V. L. G. Nayagam, and R. Ponalagusamy, "A complete ranking of incomplete interval information," Expert Systems with Applications, vol. 41, no. 4, pp. 1947-1954, 2014.

[38] Y. Zhang, P. Li, Y. Wang, P. Ma, and X. Su, "Multiattribute decision making based on entropy under interval-valued intuitionistic fuzzy environment," Mathematical Problems in Engineering, vol. 2013, Article ID 526871, 8 pages, 2013.

[39] C. Wei and Y. Zhang, "Entropy measures for interval-valued intuitionistic fuzzy sets and their application in group decisionmaking," Mathematical Problems in Engineering, vol. 2015, Article ID 563745, 13 pages, 2015.

[40] X. Tong and L. Yu, "A novel MADM approach based on fuzzy cross entropy with interval-valued intuitionistic fuzzy sets," Mathematical Problems in Engineering, vol. 2015, Article ID 965040, 9 pages, 2015.

[41] J. Wu and F. Chiclana, "Non-dominance and attitudinal prioritisation methods for intuitionistic and interval-valued intuitionistic fuzzy preference relations," Expert Systems with Applications, vol. 39, no. 18, pp. 13409-13416, 2012.

[42] J. Wu and F. Chiclana, "A risk attitudinal ranking method for interval-valued intuitionistic fuzzy numbers based on novel attitudinal expected score and accuracy functions," Applied Soft Computing, vol. 22, pp. 272-286, 2014.

[43] Z.-S. Xu, "Methods for aggregating interval-valued intuitionistic fuzzy information and their application to decision making," Control and Decision, vol. 22, no. 2, pp. 215-219, 2007.

[44] W. K. M. Brauers and E. K. Zavadskas, "The MOORA method and its application to privatization in a transition economy," Control and Cybernetics, vol. 35, no. 2, pp. 445-469, 2006.

[45] W. K. M. Brauers and E. K. Zavadskas, "Project management by MULTIMOORA as an instrument for transition economies," Technological and Economic Development of Economy, vol. 16, no. 1, pp. 5-24, 2010.

[46] W. K. M. Brauers and E. K. Zavadskas, "Multimoora optimization used to decide on a bank loan to buy property,"
Technological and Economic Development of Economy, vol. 17, no. 1, pp. 174-188, 2011.

[47] W. K. Brauers and E. K. Zavadskas, "Robustness of MULTIMOORA: a method for multi-objective optimization," Informatica, vol. 23, no. 1, pp. 1-25, 2012.

[48] D. Streimikiene, T. Balezentis, I. Krisciukaitien, and A. Balezentis, "Prioritizing sustainable electricity production technologies: MCDM approach," Renewable and Sustainable Energy Reviews, vol. 16, no. 5, pp. 3302-3311, 2012.

[49] E. K. Zavadskas, J. Antucheviciene, J. Saparauskas, and Z. Turskis, "MCDM methods WASPAS and MULTIMOORA: verification of robustness of methods when assessing alternative solutions," Economic Computation and Economic Cybernetics Studies and Research, vol. 47, no. 2, pp. 5-20, 2013.

[50] E. K. Zavadskas, J. Antucheviciene, J. Saparauskas, and Z. Turskis, "Multi-criteria assessment of facades alternatives: peculiarities of ranking methodology," Procedia Engineering, vol. 57, pp. 107-112, 2013.

[51] Z. Wang, K. W. Li, and W. Wang, "An approach to multiattribute decision making with interval-valued intuitionistic fuzzy assessments and incomplete weights," Information Sciences, vol. 179, no. 17, pp. 3026-3040, 2009.

[52] W. K. M. Brauers, A. Baležentis, and T. Baležentis, "Multimoora for the EU member States updated with fuzzy number theory," Technological and Economic Development of Economy, vol. 17, no. 2, pp. 259-290, 2011.

[53] F. Herrera and L. Martinez, "A 2-tuple fuzzy linguistic represent model for computing with words," IEEE Transactions on Fuzzy Systems, vol. 8, no. 6, pp. 746-752, 2000.

[54] A. Baležentis and T. Baležentis, "An innovative multi-criteria supplier selection based on two-tuple MULTIMOORA and hybrid data," Economic Computation and Economic Cybernetics Studies and Research, vol. 45, no. 2, pp. 37-56, 2011.

[55] A. Baležentis and T. Baležentis, "A novel method for group multi-attribute decision making with two-tuple linguistic computing: supplier evaluation under uncertainty," Economic Computation and Economic Cybernetics Studies and Research, vol. 45, no. 4, pp. 5-30, 2011.

[56] A. Baležentis, T. Baležentis, and W. K. M. Brauers, "Personnel selection based on computing with words and fuzzy MULTIMOORA," Expert Systems with Applications, vol. 39, no. 9, pp. 7961-7967, 2012.

[57] A. Baležentis, T. Baležentis, and W. K. M. Brauers, "MULTIMOORA-FG: a multi-objective decision making method for linguistic reasoning with an application to personnel selection," Informatica, vol. 23, no. 2, pp. 173-190, 2012.

[58] D. Stanujkic, N. Magdalinovic, S. Stojanovic, and R. Jovanovic, "Extension of ratio system part of MOORA method for solving decision-making problems with interval data," Informatica, vol. 23, no. 1, pp. 141-154, 2012.

[59] D. Stanujkic, N. Magdalinovic, R. Jovanovic, and S. Stojanovic, "An objective multi-criteria approach to optimization using MOORA method and interval grey numbers," Technological and Economic Development of Economy, vol. 18, no. 2, pp. 331-363, 2012.

[60] S. Karlin and W. J. Studden, Tchebycheff Systems: With Applications in Analysis and Statistics, Interscience Publishers, New York, NY, USA, 1966.

[61] D.-F. Li, "Extension principles for interval-valued intuitionistic fuzzy sets and algebraic operations," Fuzzy Optimization and Decision Making, vol. 10, no. 1, pp. 45-58, 2011. 
[62] H. Zhao, Z. Xu, M. Ni, and S. Liu, "Generalized aggregation operators for intuitionistic fuzzy sets," International Journal of Intelligent Systems, vol. 25, no. 1, pp. 1-30, 2010.

[63] C. L. Dym, Principles of Mathematical Modeling, Elsevier Academic Press, Boston, Mass, USA, 2nd edition, 2001.

[64] J. C. Pomerol and S. Barbara-Romero, Multicriterion Decision in Management: Principles and Practice, Kluwer Academic Publishers, Boston, Mass, USA, 2000.

[65] D. J. Sheskin, Handbook of Parametric and Nonparametric Statistical Procedures, Chapman and Hall, Boca Raton, Fla, USA, 5th edition, 2011.

[66] P. Vincke, Multicriteria Decision-Aid, John Wiley \& Sons, Chichester, UK, 1992.

[67] V. M. Ozernoy, "Choosing the best multiple criteria decisionmaking method," INFOR, vol. 30, no. 2, pp. 159-171, 1992.

[68] M. Aruldoss, T. M. Lakshmi, and V. P. Venkatesan, "A survey on multi criteria decision making methods and its applications," American Journal of Information Systems, vol. 1, no. 1, pp. 31-43, 2013.

[69] A. Mardani, A. Jusoh, and E. K. Zavadskas, "Fuzzy multiple criteria decision-making techniques and applicationstwo decades review from 1994 to 2014," Expert Systems with Applications, vol. 42, no. 8, pp. 4126-4148, 2015.

[70] P. Wang, Y. Li, Y.-H. Wang, and Z.-Q. Zhu, "A new method based on TOPSIS and response surface method for MCDM problems with interval numbers," Mathematical Problems in Engineering, vol. 2015, Article ID 938535, 11 pages, 2015.

[71] F. Smarandache, "A geometric interpretation of the neutrosophic set-a generalization of the intuitionistic fuzzy set," in Neutrosophic Theory and Its Applications, F. Smarandache, Ed., Europa Nova, Brussels, Belgium, 2014.

[72] J. J. Peng, J. Q. Wang, H. Y. Zhang, and X. H. Chen, "An outranking approach for multi-criteria decision-making problems with simplified neutrosophic sets," Applied Soft Computing, vol. 25, pp. 336-346, 2014.

[73] Y. Deng, "D numbers: theory and applications," Journal of Information and Computational Science, vol. 9, no. 9, pp. 24212428, 2012.

[74] X. Deng, X. Lu, F. T. Chan, R. Sadiq, S. Mahadevan, and Y. Deng, "D-CFPR: D numbers extended consistent fuzzy preference relations," Knowledge-Based Systems, vol. 73, pp. 61-68, 2015. 


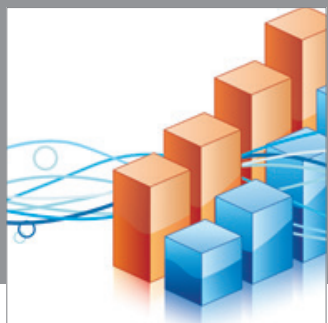

Advances in

Operations Research

mansans

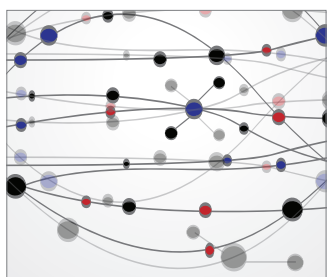

The Scientific World Journal
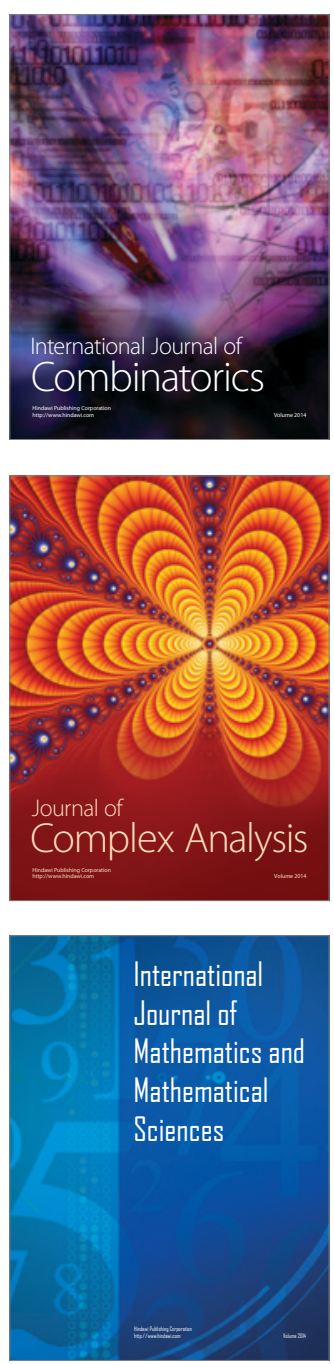
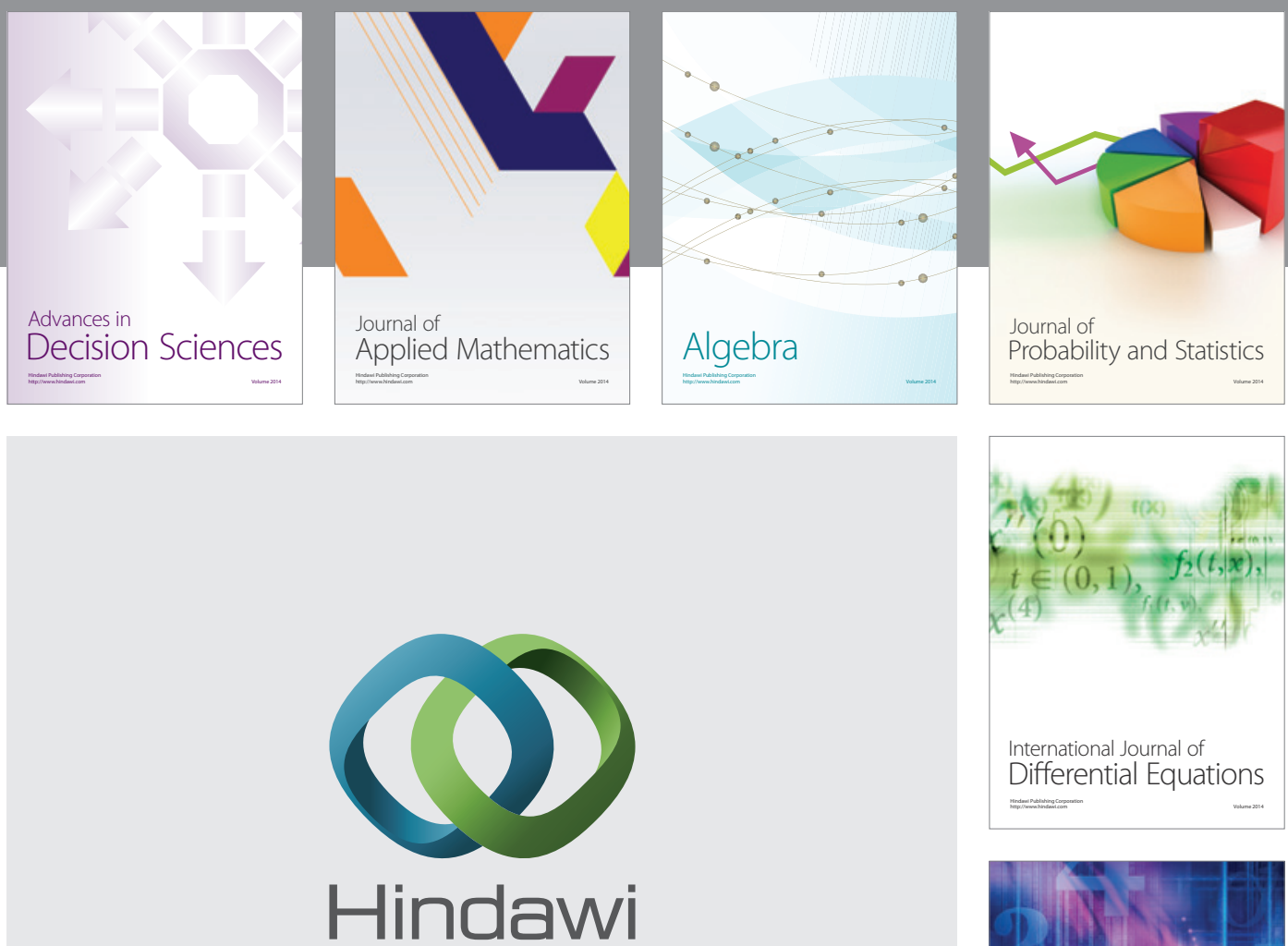

Submit your manuscripts at http://www.hindawi.com
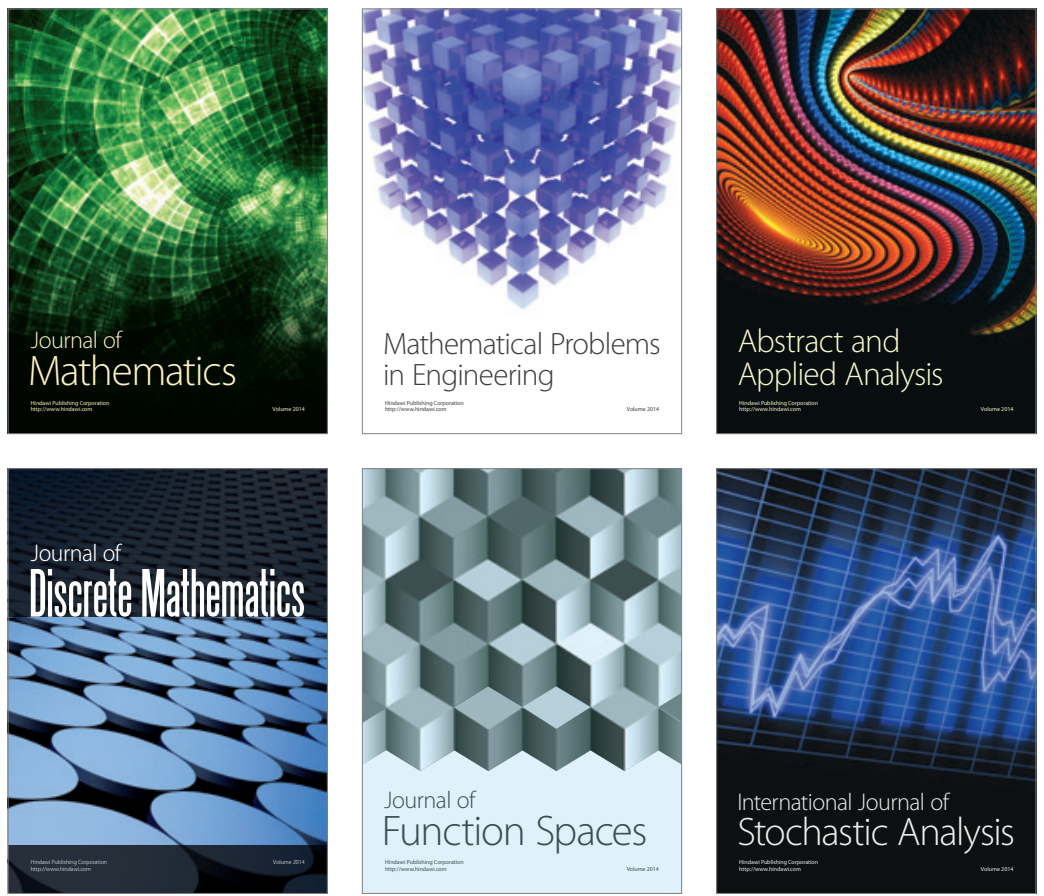

Journal of

Function Spaces

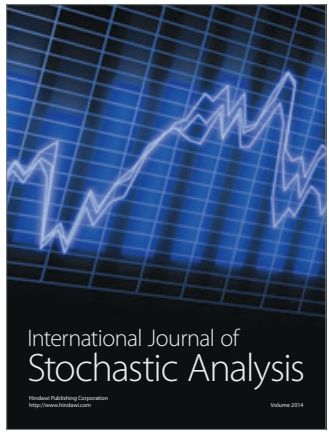

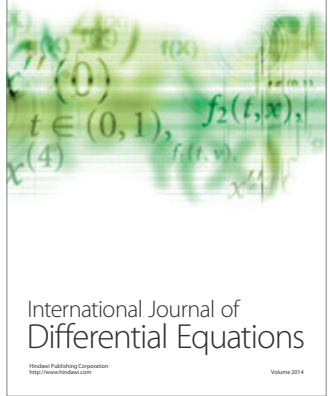
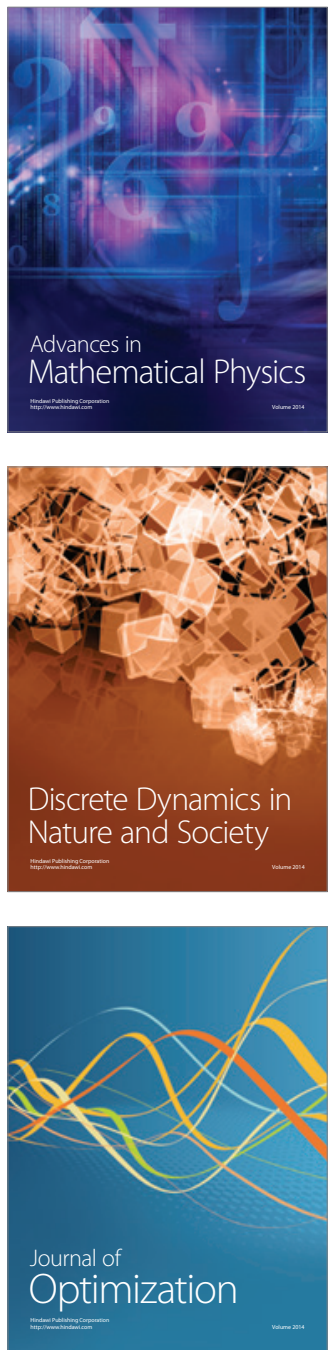